\title{
Análisis del recargo en los procesos de determinación tributaria realizados por el S.R.I. de Ecuador
}

\author{
URL: http://revistas.uta.edu.ec/erevista/index.php/bcoyu/article/view/718 DOI: http://dx.doi.org/10.31164/bcoyu.22.2019.718
}

\section{Eduardo Paredes-Paredes ${ }^{1}$; Bryan Arévalo-Bassante ${ }^{2}$}

Fecha de recepción: 7 de mayo de 2019

Fecha de aceptación: 1 de agosto de 2019

\section{Resumen}

La presente investigación tiene como objetivo analizar la naturaleza sancionatoria e indemnizatoria del recargo en los procesos de determinación tributaria. El trabajo evidencia como problema las diferentes interpretaciones realizadas por juristas y doctrinarios, a partir de la aprobación de la Ley Reformatoria para la Equidad Tributaria del año 2007, artículo 2, que modificó al Art. 90 del Código Orgánico Tributario. Para esto, desde un diseño cualitativo, mediante el método de investigación exegético, se revisó el sentido de la norma, complementado con jurisprudencia y entrevistas. Finalmente se presenta como resultado la doble naturaleza del recargo aplicado a la obligación tributaria.

Palabras claves: Recargo, determinación tributaria, administración tributaria, contribuyente

\section{Abstract}

The objective of the present research is to analyze the sanctioning and compensatory nature of the surcharge in the tax determination processes. The work presents as a problem the different interpretations made by jurists and doctrinaires, because of the approval of the Reform Law for Tax Equity in the year 2007, article 2 that modified Art. 90 of the Organic Tax Code. Based on a qualitative design, through the method of exegetical research, the meaning of the norm was revised, complemented with jurisprudence and interviews. Finally, the double nature of the surcharge applied to the tax obligation is presented as a result.

Keywords: Surcharge, tax determination, tax administration, taxpayers

\section{Introducción}

En el Ecuador se realizan periódicamente cambios al ordenamiento jurídico, que ocasionan una vulneración al derecho de la seguridad jurídica ${ }^{3}$ consagrado en la Constitución de la República del Ecuador - CRE, por cuanto, se modifican las normas tributarias que en varios casos acarrean una afectación económica para los sujetos pasivos; como por ejemplo, entre estas reformas, se incorporó por medio de la Ley Reformatoria para la Equidad Tributaria del Ecuador en el año 2007 la figura conocida como recargo tributario, que modificó al art. 90 del Código Tributario, que obliga al pago de un $20 \%$ adicional de recargo sobre la obligación tributaria determinada por el sujeto activo; con el mencionado cambio normativo, aparecieron una serie de interpretaciones en cuanto a su aplicación, además de realizarse algunos procesos legales tanto en la Corte Constitucional como en la Corte Nacional de Justicia, relacionados a resolver temas de constitucionalidad e irretroactividad respectivamente, considerando, la naturaleza de ésta figura jurídica, partiendo de varios enfoques, como la de establecer si es de carácter sancionatorio o indemnizatorio, lo cual, se analiza en el presente trabajo, con la información recopilada de fuentes primarias, secundarias y expertos en la materia.

Existe una confusión con la aplicación de la figura del: recargo, los intereses y las multas; lo cual es importante contrastar desde el punto de vista de la Administración Tributaria, especialmente por parte de la Central, en la que se encuentra el Servicio de Rentas Internas - S.R.I.; en vista de que uno de los objetivos del estado radica en disminuir la evasión tributaria, mediante la aplicación del denominado recargo, los contribuyentes deben pagar un valor adicional del $20 \%$ de la obligación principal que se incluye en los valores determinados en un proceso de auditoría tributaria, como una especie de indemnización o resarcimiento que recibe el estado del sujeto pasivo que trató de pagar menos tributos y se le debió realizar un proceso determinativo, contribuyendo a aumentar la recaudación tributaria; también se lo puede considerar que tiene carácter sancionatorio, ya que el contribuyente a más de pagar los intereses ${ }^{4}$ y multas ${ }^{5}$ por la falta de declaración, debe pagar un valor adicional de recargo sobre la obligación principal.

El trabajo contiene la conceptualización de temas como: el recargo, clases, la obligación tributaria, la facultad determinadora, la determinación Tributaria, la aplicación del Recargo de acuerdo a la base legal, entre otros, que sirven para entender de forma más concreta el uso y finalidad de la aplicación del recargo del $20 \%$ en las determinaciones tributarias por parte de la Administración Tributaria. Existe varias investigaciones que guardan relación con el objeto de estudio, en- tre los más relevantes se pueden enunciar a: Cevallos (2014), Colcha (2012), Endara (2011), Oñate (2014), Ortiz (2014); conforme se presentan los aspectos más relevantes.

El Estatuto Tributario de Colombia (2018) en sus arts. 646 y 647 determina la figura jurídica del recargo tributario, similar al existente en la legislación ecuatoriana, con la diferencia que son llamados, nombrados y conocidos como sanción por corrección aritmética y sanción inexactitud. Pues bien, dichos articulados contemplan la forma de procedencia de dichas sanciones por la mala errónea declaración realizada por los contribuyentes, considerándose el saldo a favor del Estado y a la vez el de los sujetos pasivos, en la primera sanción básicamente se efectuará sobre el valor principal total a pagar y en la segunda sanción sobre el saldo inferior recayendo en que no se formaliza el recargo tributario ni tampoco da paso a la existencia de dicha figura, pues lo que se genera es una multa la cual acarrea otra connotación muy aparte de la temática.

El Estatuto Tributario Colombiano (2018) resalta en sus artículos 715, 643 y 812 instituye que la respectiva sanción que se genera cuando los sujetos pasivos no han cumplido con el pago total de sus obligaciones tributarias o que han hecho caso omiso del mismo dando cavidad al cobro de por medio a una multa por mora, dando paso al cumplimento normativo previstos en el Estatuto Tributario (2018) art. 634 y 635 el cual permite a la administración hacer uso del mismo con el fin de que los contribuyentes no evadan sus impuestos y tampoco afecten a la economía del fisco. Y de esa forma buscar el bien entre el Estado y los sujetos pasivos.

En Argentina el Código Tributario (2014), al igual que las normativas de los países que se ha manifestado anteriormente también se puede tomar en consideración sus arts. 9, 10 y 11 menciona de forma explícita las facultades las cuales le otorgan el poder de ejercer de forma autónoma el ejercicio de sus funciones en lo que concierne a control y administración tributaria, facultades que por ley debe cumplirse con total y absoluta cabalidad. De igual forma dicha ley en art. 62 determinar el pago de compensación por parte del sujeto pasivo cuando este adeude cierto valor económico a favor del fisco, no estipulando ni manifestando recargo alguno o adicional cuando la administración tributaria detecte pagos incompletos o a la vez los contribuyentes adeuden un valor económico al Estado.

Tomando en consideración a la legislación peruana también se puede mencionar en base al Código Tributario peruano, en el libro Il, los artículos 73 , 76 y 77 , instituyen la facultad de determinación y fiscalización de la administración tributaria, la cual faculta a la administración tributaria de aplicar multas a los contribuyentes cuando éste ha encontrado anomalías en el pago de las declaraciones tributarias el mismo que es considerado como sanción en dicha legislación, dicha norma legal brinda al sujeto pasivo la oportunidad de justificar en el plazo predeterminado para que aclare a la administración tributaria el reparo de las observaciones realizadas, siendo el fisco quien incurre con el gasto necesario que conlleva una determinación tributaria cuando ha existido la omisión del pago de la obligación tributaria, dejando de lado cualquier tipo de recargo adicional.

La falta de definición normativa del recargo, produce inconvenientes al contribuyente, o sujeto pasivo, existe un perjuicio al bienestar económico basándose en sustentaciones legales; lo cual genera diferentes interpretaciones, cabe recalcar que para la administración tributaria el recargo tributario es netamente de carácter indemnizatorio, pues este porcentaje recompensa el trabajo ejecutado por parte del S.R.I (Cevallos, 2014).

Concordando con el trabajo de Javier Bustos (2013) referente a la función de indemnizatoria y resarcitoria del recargo tributario en base al análisis de la sentencia No. 008-12-SIN-CC de fecha 10 de Abril del 2012, la Corte Constitucional se puede manifestar que el recargo, posee una naturaleza jurídica de carácter indemnizatorio, disuasivo y resarcitorio, que contribuye a que el sujeto pasivo cumpla con sus obligaciones tributarias de una forma voluntaria, sin esperar a que una Administración Tributaria, como el S.R.I., le realice un proceso de determinación; sin embargo, el hecho de realizarse las verificaciones correspondientes, implica que el estado deba incurrir en gastos, lo cual, de alguna forma debe ser recom-

Ontificia Universidad Católica del Ecuador. Escuela de Jurisprudencia / Administración de Empresas. Ambato -Ecuador. E-mail: eparedes@puces Pontifici Univeridad Cóll

Art. 82 CRE El derecho a la seguridad jurídica se fundamenta en el respeto a la Constitución y en la existencia de normas jurídicas previas, claras, públicas y aplicadas por las autoridades competentes.

"Los intereses a cargo del sujeto pasivo se causan sobre las obligaciones tributarias que no fueron satisfechas en el tiempo que la ley establece y sin necesidad de resolución administrativa alguna, desde la fecha de su exigibilidad hasta la de su extinción (artículo 21 del Código Tributario - artículo 99 de la Ley de Régimen Tributario Interno).

La multa es una de las penas aplicables a las infracciones tributarias, que forman parte de las sanciones sin necesidad de resolución administrativa, que impone la Administración Tributaria cuando los sujetos pasivos que dentro de 'La multa es una de las penas aplicables a las infracciones tributarias, que forman parte de las sanciones sin necesidad de resolución administrativa, que impone la Administración Tributaria, cuando los sujetos p 
pensado y rembolsado al sujeto activo del tributo. Los doctrinarios concuerdan que el recargo es un valor adicional que se deben pagar los contribuyentes por una mala obligación tributaria y que dicho porcentaje no sostiene un estudio técnico que indique su efectividad que este pueda dar.

De acuerdo a lo determinado por parte de la Sala de lo Contencioso Tributario de la Corte Nacional de Justicia referente al recargo tributario en las sentencias 3912009 de 9 de agosto de 2010, la sentencia 310-2009 de 30 de agosto de 2010 y de la sentencia 138-2010 de 24 de marzo de 2011, da a conocer el fallo de triple reiteración en el que se ratifican y manifiestan que el cobro del recargo del $20 \%$ que se aplica sobre el valor principal ejerciendo el sujeto activo su facultad y potestad determinadora de manera directa, poseyendo una característica de naturaleza sancionadora, debido a que busca resarcir o disuadir un mal incumplimiento de la obligación tributaria, por lo cual esto da como consecuencia, de que no cabe que se aplique el recargo del 20\% a las determinaciones iniciadas con anterioridad a la entrada en vigencia de la reforma, esto es, al 29 de diciembre de 2007 y de igual forma no debe aplicarse a las determinaciones iniciadas con posterioridad a esa fecha, pero que se refieran a ejercicios económicos anteriores al 2008.

El recargo tributario es considerado de forma diferente en las varias legislaciones que la aplican, considerándola de carácter tanto indemnizatoria y a la vez como sancionatoria, tomando en consideración la comprobación y verificación de contravención tributaria alguna, de tal modo que para que se dé la infracción debe existir la falta de declaración o la omisión del pago en el tiempo predeterminado por la normativa legal, se la comprenderá como la consecuencia pecuniaria que reafirma como un estatuto de sanción (Endara, 2011). El recargo envuelve el deber de brindar una determinada cifra económica a la administración tributaria considerando especialmente del valor principal a pagar (Colcha, 2012).

Según Ortiz (2014), la falta de justificación referente a la figura jurídica del recargo da paso, a una interpretación que, en última instancia, favorecería al sujeto pasivo, efectuando un castigo que puede favorecer o perjudicar al contribuyente, es entonces la evidencia del vacío legal del cual es proveniente su originalidad y función principal ,por lo que los legisladores deben mejorarla para que su ambigüedad no contraiga confusiones ni mucho menos más perjuicios en especial a los sujetos pasivo.

Cuando existe alguna infracción tributaria y está pueda ser voluntaria o no por parte de los sujetos pasivos, se da el cobro del interés y la multa, adicional al cobro del recargo, esto acarrea a la obligación de los sujetos pasivos a cumplir el pago total de sus impuestos en el tiempo predominado, con la finalidad de evitar cualquier tipo de sanción o amonestación pecuniaria que afecte al bienestar económico de los contribuyentes (Oñate 2014). De lo manifestado por los diferentes autores se determina que el recargo tributario es una figura jurídica instituida en la legislación ecuatoriana con el fin de que el Estado incremente su recaudación fiscal, pero el recargo del $20 \%$ es de carácter sancionatorio ya que de forma directa castiga a los contribuyentes de manera en la que existe una afectación económica al sujeto pasivo y a la vez es resarcitoria debido a que es un valor que recompensa a la administración tributaria por ejercicio del costo que tiene el ejercer una auditoría tributaria.

\section{Fundamentos Teóricos}

Recargo

El recargo tributario del $20 \%$ es el valor adicional que se aplica a la obligación principal por parte del S.R.I. y cualquier Administración Tributaria en los procesos de determinación, cuando no se ha pagado en el tiempo establecido. Según Lascano (2010), el recargo tiene que ver con el cobro del incremento al valor principal de la obligación tributaria, la misma que se instituye por medio de la base del tributo ya existente.

El recargo tributario es el incremento de una cuota líquida sobre la base imponible el cual consiste en porcentaje fijo que se establece sobre el valor total a pagar. Con el fin de que el fisco recaude más ingresos económicos por la omisión de los contribuyentes en sus obligaciones tributarias o por no cumplir con sus obligaciones a tiempo oportuno (Clavijo Hernández, 2013).

\section{Clases de Recargo}

De acuerdo a los doctrinarios, dentro de las clases de recargos, se establecen tres clases o tipos de recargos: recargo resarcitorio, recargo sancionatorio y el recargo mixto.

El recargo resarcitorio según Ballarín (2016), el recargo resarcitorio tiene como finalidad el establecimiento de compensar o indemnizar un perjuicio ocasionado a la administración tributaria. El recargo resarcitorio es aquel recargo que se emplea con la finalidad de compensar dicho de mejor manera de indemnizar por la lesión efectuada al fisco en la omisión de la obligación por parte del contribuyente (Toscano, 2006). Por lo tanto, se puede determinar que la indemnización primero se da por la existencia por parte de los contratantes bajo el consentimiento de la voluntad y por otro lado reafirmar que está compuesto por lucro cesante y daño emergente. Lo cual en materia tributaria esto es subjetivo debido a que sería necesario emplear diferentes inconsistencias para lograr establecer cuando se considera daño emergente y cuando se refiere a lucro cesante a favor del fisco o Estado con el cual se puede resarcir dicho daño.

El recargo sancionatorio constituye una pena los recargos establecidos sobre una deuda tributaria a través de los cuales se pretende intimidar a los sujetos pasivos de la potestad de imposición para que realicen una determinada conducta y castigarlos en el caso de que no cumplan (Rodríguez, 2005). En el Derecho Tributario es la multa y crea una nueva figura tributaria denominada "recargo", que es simplemente cambiar de nombre a la multa, para aumentar la sanción ya establecida a través de la multa.

El recargo mixto incluye los dos aspectos anteriores, es decir cumplen una función en la parte indemnizatoria y en parte sancionatoria. El recargo se considera mixto porque busca sancionar un comportamiento a la vez de indemnizar al fisco por el daño que le pudo haber producido el incumplimiento (Clavijo, 2013).

\section{Obligación Tributaria}

Según Elizalde (2014), la obligación tributaria consiste en el vínculo obligatorio en probidad entre los entes acreedores del tributo, el fisco o Estado y los sujetos pasivos o también conocidos como contribuyentes, en el cual debe compensarse una cierta prestación en dinero, especie o servicios apreciados en dinero, al comprobarse el hecho generador preestablecido en la ley.

Al hablar de obligación tributaria se refiere netamente al cumplimiento de la obligación por parte de los contribuyentes, acatando y cumpliendo con total cabalidad con el fisco, cumpliendo con la ley para así evitar sanciones o multas que pueden afectar al sujeto pasivo (Perez,2005).

A continuación, se presenta el concepto de obligación tributaria que consta en el Código Tributario (2018):

Obligación tributaria es el vínculo jurídico personal existente entre el estado o las entidades acreedoras de los tributos y los contribuyentes responsables de aquellos, en virtud del cual debe satisfacerse una prestación en dinero especies o servicios apreciables en dinero al verificarse el hecho generador previsto por la ley. (art.15).

Para que se produzca el nacimiento de la obligación tributaria, es un requisito sine qua non que se dé cumplimiento con el presupuesto de hecho previsto en la Ley, éste recibe el nombre de Hecho Generador, aunque algunos tratadistas han adoptado otras denominaciones como hipótesis de incidencia o hecho imponible que constituye el núcleo mismo de la relación Jurídica Tributaria.

\section{Determinación Tributaria}

Según Durango (2016), la determinación es la acción o conjunto de actos que provienen de los contribuyentes o derivados de la Administración Tributaria, direccionados a contribuir o declarar la preexistencia de la base imponible, el hecho generador y la cuantía del tributo. La determinación tributaria constituye el análisis de todos los elementos conformantes del tributo para establecer cuando se ha configurado la obligación tributaria y con esta finalidad la administración debe realizar la verificación, complementación o enmienda de las declaraciones de los contribuyentes o responsables.

En el Código Tributario (2018): “La determinación es el acto o conjunto de actos provenientes de los sujetos pasivos o emanados de la administración tributaria, encaminados a declarar o establecer la existencia del hecho generador, de la base imponible y la cuantía de un tributo" (art. 87). La normativa tributaria es muy clara respecto a sus atribuciones y facultades, por lo tanto esto significa que la determinación no constituye una facultad moderada del órgano administrativo. La determinación tiene finalidades precisas como son declarar o establecer. Al constituir un acto o conjunto de actos reglados, esto significa que la determinación no constituye una facultad moderada del órgano administrativo. La determinación tiene finalidades precisas como son declarar o establecer.

\section{Aplicación del Recargo de acuerdo a la base lega}

El Código Tributario (2018):

Determinación por parte del sujeto activo. - El sujeto activo establecerá la obligación tributaria, en todos los casos en que se ejerza su potestad determinadora, conforme al artículo 68 de este Código, directa o presuntivamente. Adicionado, Art.2, Ley Reformatoria para la Equidad Tributaria de Ecuador. La obligación tributaria así determinada causará un recargo del 205 sobre el principal (Art. 90).

La aplicación del recargo tributario del 20\% en las actas de determinación tributaria se realiza una vez terminado el proceso de verificación, cruce de información, análisis de las declaraciones, informes, sistemas, procesos y demás documentos, se levantará la correspondiente Acta Final de Determinación, en la cual se establecerá los valores a favor de la administración tributaria por concepto de multas, intereses y adicional a esto el recargo del 20\% sobre la obligación. Este recargo es la institución jurídica objeto del presente estudio. 
En la práctica, se conoce que el Servicio de Rentas Internas realiza los procesos de determinación tributaria a los contribuyentes que presentan riesgos tributarios en cuanto a la veracidad en la presentación de sus declaraciones de impuestos, especialmente cuando existen diferencias a favor de la administración tributaria; por lo cual, debe aplicar la figura del recargo como forma adicional de disuadir al sujeto pasivo para que efectúe una correcta determinación sus obligaciones tributarias.

\section{Metodología}

La investigación se desarrolló desde un enfoque critico propositivo porque analizó la teoría y la normativa en torno al fenómeno jurídico del recargo tributario, se lo plantea como la alternativa para la investigación social debido a que privilegia la interpretación, comprensión y explicación del fenómeno del recargo tributario en la sociedad. Buscando una crítica reflexiva, induciendo a esta crítica para considerarla como la transformación de la realidad referente al recargo tributario. Para ello, se efectuó un modelo cualitativo, debido a que se partió de conceptos doctrinarios generales para entender el impacto sobre la aplicación del recargo tributario en las determinaciones tributarias y se empleó el método el exegético puesto que se toma en cuenta como punto de partida una norma de derecho positivo, la Ley Reformatoria para la equidad Tributaria, para a partir de este cuerpo legal realizar un análisis respecto a su alcance y afectación pragmática en los ciudadanos y sus derechos fundamentales, con el fin de realizar un análisis de la norma respecto del alcance y la afectación que ha constituido el recargo tributario.

Adicionalmente se empleó fuente primaria y secundaria; mismas que permitieron dar sustento a la presente Investigación; para la recolección de la información se emplearon entrevistas aplicadas a expertos en materia tributario, entre los cuales se consideraron a funcionarios del Departamento Jurídico y Auditoría Tributaria del Servicio de Rentas Internas - SRI Zonal 3, al ser la institución que determina y aplica el recargo del $20 \%$ en las determinaciones tributarias, además de la intervención de una experta en materia tributaria y los distinguidos miembros que conforman el Tribunal de lo Contencioso Administrativo y Tributario del Consejo de la Judicatura de Tungurahua.

\section{Resultados}

De conformidad con la doctrina y jurisprudencia de tan relevante tema de interés social, se puede manifestar que el recargo tributario posee como una finalidad de aumentar la recaudación por parte del Estado, sin tomar en consideración los daños que el cobro del recargo es inapropiado debido a que debe establecerse un porcentaje apropiado en base proporcional, y más no bien no un porcentaje fijo para todos.

En base a las entrevistas realizadas al tribunal de lo Contencioso Administrativo y Tributario, como a la abogada experta y a los cinco servidores públicos principales de los Departamentos de: Auditoría, Gestión y Jurídico del Servicio de Rentas Internas se pudo determinar que la naturaleza del recargo tributario busca básicamente incrementar y aumentar los ingresos en favor del fisco o del Estado. Además, es de carácter indemnizatorio y sancionatorio, el primero debido a que el contribuyente debe resarcir el costo o valor que le cuesta a la Administración Tributaria detectar las anomalías que pueden presentarse y detectarse por medio de las auditorias tributarias; y, el segundo, debido a que es una amonestación pecuniaria en contra del contribuyente adicional al valor total de la determinación tributaria por la omisión del pago o por el incumplimiento de la obligación tributaria, de conformidad como se presenta en la tabla 1.

$$
\begin{gathered}
\text { Tabla 1. Análisis de las entrevistas realizadas a los miembros del Tribunal de lo Contencioso Administrativo y } \\
\text { Tributario, como a los funcionarios del departamento Jurídico y de Autoría Tributaria }
\end{gathered}
$$

\begin{tabular}{|c|c|}
\hline ENTREVISTADOS & ANÁLISIS \\
\hline $\begin{array}{l}\text { Dr. Walter Garnica (Juez de lo } \\
\text { Contencioso Administrativo y } \\
\text { Tributario) }\end{array}$ & $\begin{array}{l}\text { Es claro mencionar que el recargo tiene un carácter sancionador y por lo tanto si } \\
\text { afecta a los contribuyentes ya que el cobro de un recargo siempre afectará el bienestar } \\
\text { económico del contribuyente y a la vez el bienestar de la actividad económica a la que } \\
\text { se dedique o realice y por lo tanto el recargo del } 20 \% \text { en el pago de las } \\
\text { determinaciones tributarias afectaría de forma directa a los contribuyentes }\end{array}$ \\
\hline $\begin{array}{l}\text { Dr. Edison Guerrero (Juez de } \\
\text { lo Contencioso Administrativo } \\
\text { y Tributario) }\end{array}$ & $\begin{array}{l}\text { Se puede considerar que el recargo que se encuentra estipulado de forma correcta en } \\
\text { el artículo } 90 \text { pues no por tener el carácter sancionatorio se lo debería considerar } \\
\text { como tal, sino más bien es sancionado por tratar o buscar de disuadir una obligación la } \\
\text { cual debe cumplir y no puede hacer caso o miso del mismo, por lo tanto, al generar un } \\
\text { gasto extra o adicional a la administración pública este debe ser reparado en este caso } \\
\text { sería por parte del contribuyente }\end{array}$ \\
\hline $\begin{array}{l}\text { Dr. Hernán salinas (Juez de lo } \\
\text { contencioso administrativo y } \\
\text { tributario) }\end{array}$ & $\begin{array}{l}\text { En mi criterio personal el recargo del } 20 \% \text { en las doterminaciones tributarias } \\
\text { establecidas en el Art. } 90 \text { del Código Tributario, no es adecuado, porque viene a ser } \\
\text { una medida confiscatoria al patrimonio de los contribuyentes, al cobrar una cantidad } \\
\text { adicional a la determinación tributaria, lo cual implica que esta sea inconstitucional; } \\
\text { además porque al no realizar el sujeto pasiva la declaración conforme le correspondí,, } \\
\text { el sujeto activo al momento de la determinación ya cobra intereses y multa, } \\
\text { establecerse adicionalmente el recargo del } 20 \% \text { violenta principios constitucionales } \\
\text { previstos en el Art. } 76 \text { de la Constitución de la República, como por ejemplo; nadie } \\
\text { puede ser juzgado más de una vez por la misma causa y materia; nadie podrá ser } \\
\text { privado del derecho a la defensa. }\end{array}$ \\
\hline
\end{tabular}$$
\text { del Servicio de Rentas Internas y a la distinguida abogada experta }
$$
materia tributaria) forma pria una sanción debería haber una pena establecida y debería buscarse en la acción en que el contribuyente ha realizado el dolo en este caso nosotros no podemos determinar si hubo o no hubo dolo dentro de la actuación del contribuyente porque en muchos casos puede tratarse de un error o de una omisión respecto de los valores que constan en la declaración por lo tanto no se ha verificado dolo respecto del tema de la acción por lo tanto no puede ser catalogado como una sanción en el sentido amplio de la palabra.

Dra. María Augusta Cevallos Tributariamente es un tema bastante delicado sobre el tema del recargo del 20\%, el (Abogada del S.R. zonal 3) mismo que tiene dos finalidades la una es de tener un efecto sancionador en un aspecto general pero también indemnizatorio respecto del trabajo que la administración debe realizar para poder recaudar los tributos que no han sido pagados en forma oportuna. De acuerdo a mi criterio personal es adecuado el cobro del $20 \%$ del recargo sobre el principal por el esfuerzo adicional que la administración tiene que realizar a fin de recaudar los tributos de manera adecuada

Ing. Fabián Mera (Director del El cobro del recargo tributario establecido en el art.90 del Condigo Tributario no es el departamento de autoría adecuado, a pesar que se ha presentado la debida impugnación por tributaria) inconstitucionalidad a la Corte Constitucional, éste órgano jurisdiccional se menciona en su fallo en el sentido de que es un valor, no es una sanción como tal sino que es un valor que tiene que restituirse a la administración tributaria por haberse tomado la molestia de hacer una determinación, el cual es su trabajo el mismo que se le paga, por lo tanto no es procedente el cobro del recargo del $20 \%$.

Ing. Doris Fiallos Realmente desde que empezamos con el tema del cobro del $20 \%$ del recargo Ing. Doris Fiallos nersonas naturales de como que constituye un castigo adicional o se podría decir una especie de sanción auditoria tributaria) adicional por el tema de hacer mal la determinación de sus impuestos vía sus declaraciones entonces básicamente a la administración tributaria igual le incurren costos adicionales para poder cumplir con esos proceso de control entonces básicamente el recargo viene de la mano con esa naturaleza a la misma vez lo que hace es sancionar el comportamiento del contribuyente y de cierta manera poder un poco compensar la actuación que tiene la administración tributaria en cuanto a costos compensar la actuación que tiene la administrativos aue incurren nor los control

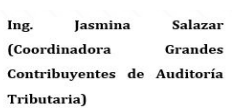
cobro del recargo del $20 \%$ es el adecuado por cuanto con este valor administración tributaria lo que hace es recuperar un poco la carga administrativa que tienen realizar los procesos determinativos; es decir, que no es lo mismo que contribuyente haya pagdo correctere craves de in determinato, compensar gasto que tiene la administración tributaria para que los funcionarios realicen este proceso

Ing. Dennis López (Jefe del La administración tributaria considera que es el adecuado el tema del cobro del Departamento de Gestión recargo puesto que el entrar en un proceso de determinativo con un contrihuyente Tributaria) trar en gastos dicionales como os a do la vificación de la información y el establecimiento de las posibles diferencias entonces al generar un costo en la administración tributaria este a través del recargo es recuperado con el pago del contribuyente esa seria la parte fundamental respecto de la aplicación del cobro del $20 \%$

Fuente: Elaboración propia a partir de entrevistas (2018)

En consideración a los criterios manifestados por los juristas, se logra establecer que la finalidad del cobro del recargo tributario es aumentar el ingreso económico del fisco, porcentaje fijo que es aplicado, dicha figura jurídica busca indemnizar costos a la administración tributaria en la identificación de anomalías en las determinaciones tributarias, pero que afecta de forma directa a la economía de los contribuyentes por su carácter sancionatorio.

Con la implementación del recargo tributario por parte de los legisladores de aquel periodo simplemente su planteamiento fue que los contribuyentes presenten de forma más correcta las declaraciones, y quienes no lo hagan de manera adecuada se atengan al pago del recargo tributario. Por lo tanto, el recargo del $20 \%$ cumple con la finalidad por el cual fue creado debido a que el nivel de declaraciones erróneas o inexactas ha disminuido considerablemente. Teniendo presente y en consideración que, para la administración tributaria, el recargo tributario no viola ni vulnera principios constitucionales por cuanto lo único que la administración tributaria establece el cobro del recargo por la omisión del cumplimiento de la obligación por parte del sujeto pasivo.

La aplicación del cobro del recargo tributario vulnera principios tributarios, debido a que la figura del recargo generó irretroactividad a los ordenamientos normativas a su debido momento, debido a que esta figura jurídica carece de total y absoluta fundamentación técnica para su implementación en la legislación ecuatoriana. Se instituye la figura con la única finalidad de que el Estado perciba mayores ingresos tributarios y que dicha sanción debería estipularse de forma más concreta en la base legal, para de esa forma evitar diferentes interpretaciones jurídicas que se han dado, sin olvidar el perjuicio económico que ocasiona el cobro del recargo a los sujetos pasivos en la estabilidad financiera de la actividad económica a la que se dediquen.

Concordando con el trabajo de Javier Bustos (2013) referente a la función de indemnizatoria y resarcitoria del recargo tributario en base al análisis de la sentencia No. 008-12-SIN-CC de fecha 10 de Abril del 2012, la Corte Constitucional se puede manifestar que el recargo, posee una naturaleza jurídica de carácter indemnizatorio, disuasivo y resarcitorio, que contribuye a que el sujeto pasivo cumpla con sus obligaciones tributarias de una forma voluntaria, sin esperar a que una Administración Tributaria, como el S.R.I., le realice un proceso de determinación; sin 
embargo, el hecho de realizarse las verificaciones correspondientes, implica que el estado deba incurrir en gastos, lo cual, de alguna forma debe ser recompensado y rembolsado al sujeto activo del tributo. Los doctrinarios concuerdan que el recargo es un valor adicional que se deben pagar los contribuyentes por una mala obligación tributaria y que dicho porcentaje no sostiene un estudio técnico que indique su efectividad que este pueda dar.

Sobre el porcentaje del $20 \%$ del recargo, los entrevistados sostienen que es adecuado, porque permite establecer la función principal de equidad en cuanto a la capacidad económica de los contribuyentes, resaltando que posee la naturaleza sancionatoria, es decir, que por los errores identificados y encontradas por parte de la administración tributaria en las declaraciones de los contribuyentes, se debe cobrar un valor adicional como sanción del incumplimiento. Dicho recargo ha permitido y ha servido para poder obtener un mejor comportamiento y mitigar la brecha de veracidad de las declaraciones de los sujetos pasivos

El cobro del recargo tributario a los contribuyentes tiene su relevancia en que mientras mayor recaudación obtenga el fisco, mayores serán los beneficios para la nación ya que los recursos económicos que perciba el Estado permitirán una mejor y mayor sostenibilidad financiera; sin embargo, no se considera la afectación que este puede acarrear a las pequeñas, medianas y grandes empresas, que no cuentan con la capacidad contributiva para su cumplimiento, ya que se adiciona el valor del interés, la multa en algunos casos, lo que se podría mencionar que existe una doble sanción.

\section{Conclusiones}

La figura del recargo tributario perjudica a la economía de los contribuyentes al haber establecido un porcentaje fijo del $20 \%$ como sanción para todos los sujetos pasivos; el cual, se constituye en un valor adicional sobre la obligación principal que se extingue sólo al momento en que se paga.

El recargo tributario contemplado en el Art. 90 del Código Orgánico Tributario no fundamenta y a la vez no expone de forma concreta y precisa su naturaleza jurídica; al respecto, diversos doctrinarios revisados, que señalan que el recargo, debido a su poco desarrollo conceptual, presenta anomalías en su aplicación, lo cual acarrea que se efectúen con una sucesión de diversos comentarios e interpretaciones, cada uno amparando y resguardando sus planteamientos y fundamentaciones.

El cobro del recargo tributario acarrea dos funcionamientos que son tanto sancionatorios como indemnizatorios. Varios funcionarios de la Administración Tributaria aseveran que el recargo del $20 \%$ es indemnizatorio, ya que se justifica por el trabajo adicional que realizan, el cual implica un gasto para el estado, para de esa forma garantizar la recaudación de los tributos; por otro lado, los pronunciamientos jurisdiccionales afirman que la naturaleza del recargo es sancionatoria y que no cabe lugar alguno para su justificación como un medio de compensación de la diligencia administrativa ejecutada por la facultad determinadora, que establece el valor del tributo a pagar, debido a que es una función propiamente de la Administración Tributaria.

La finalidad de la implementación del recargo tributario más allá de su naturaleza jurídica, es aplicar una sanción al contribuyente por realizar una incorrecta determinación de sus obligaciones tributarias; que se encuentra amparada por la normativa legal que le brinda la potestad a la administración tributaria para que aplique, lo que es necesario para el mejoramiento de la cultura tributaria por parte de todos los sujetos pasivos.

Las reparaciones económicas que afectan a la administración tributaria deben ser retribuidas, debido a que ocasiona un perjuicio financiero de forma directa al bienestar económico del Estado; por lo cual, el recargo tributario aplicado a los contribuyentes no busca que se resarza al Fisco, sino que, por la omisión especifica en el pago de la obligación tributaria, éste acarrea una sanción por desacato a la norma legal con respecto a la incorrecta determinación tributaria de las obligaciones por parte de los contribuyentes.

Por lo expuesto, se concluye que el recargo se considera una sanción adicional por el incumplimiento de una correcta determinación del tributo por parte de los contribuyentes, que se debe pagar sobre la obligación tributaria determinada por la Administración Tributaria y no tiene ninguna relación con el cobro del interés y la multa; su finalidad es promover el mejoramiento de la cultura tributaria. Cabe indicar que por el simple hecho de que no se encuentre estipulado en el Código Tributario en el capítulo de las sanciones, no quiere decir que no sea considerado de carácter sancionatoria.

Asimismo, de acuerdo a lo establecido en los fallos de triple reiteración de la Sala de lo Contencioso Tributario de la Corte Nacional de Justicia y las sentencias de constitucionalidad de la Corte Constitucional, referente al recargo tributario, determinan que el cobro del recargo del $20 \%$ que se aplica sobre el valor principal al ejercer, cuando el sujeto activo ejerce su facultad determinadora, posee una característica de naturaleza sancionadora, debido a que busca resarcir o disuadir un mal incumplimiento de la obligación tributaria; sin embargo, también resulta que es de carácter indemnizatorio a favor del estado, por el gasto público que implica realizar un proceso de determinación tributaria.

\section{Referencias}

Ballarín, M. (2016). Los ingresos Tributarios fuera de plazo sin requerimiento previo. (1a. d.) Madrid: Marcial Pons.

Bustos, J. (2013). La función indemnizatoria y resarcitoria del recargo tributario. Recuperado el 20 de agosto del 2018, de https://www.usfq.edu.ec/publicaciones/iurisDictio/...de... iurisdictio_015_013.pd

Carlos Mayorga vs Director General y Regional Norte del S.R.I., 60 GJ (C.C.E. 2017) Cevallos, F. (2014). Naturaleza Jurídica del Recargo, Sanción o Consecuencia de la Determinación Tributaria Por parte del Sujeto Activo. Quito, EC: Universidad Central del Ecuador. Clavijo, F. (2013). Las obligaciones tributarias accesorias. Recuperado el 20 de septiembre del 2018, de http://www.gobcan.es/haciendacanaria/downloads/Revista10/RevistaHC 10 3.pdf? $q=j q$ modal\&go=QB $\mathrm{H}$ \& width $=100 \%$ height $=90 \%$

Código Tributario (2018). Ecuador: Corporación de Estudios y Publicaciones.

Colcha, E. (2014). El recargo tributario ¿naturaleza recaudadora o sancionatoria? . Quito,

EC: Universidad Andina Simón Bolívar, Sede Ecuador.

Compañia terminal Aeroportuaria de Guayaquil S.A. vs Director Regional Sur del S.R.I.

\section{GJ (C.N.J. 2010)}

Constitución Política de Colombia. R.O. No. 868 del 29 de septiembre del 2016.

Constitución Política del Estado de Bolivia. R.O. No.123 del 28 de noviembre del 2009. Constitución Política del Perú. R.O. No.014 del 29 de diciembre de 1993.

Córdova, H. (2013). Determinación del Tributo sobre base pecuniaria. (1a. ed.). Barcelona-Pons.

Corte Nacional De Justicia (2011). Resolución s/n, de 4 de mayo de 2011. Fallos De

Triple Reiteración. Registro Oficial No. 471 de 16 de junio de 2011. Recuperado el 10 de abri de 2019 de: http://www.cortenacional.gob.ec/cnj/images/pdf/precedentes/8\%20triple\%20reiteracion\%20tributario.pdf

Diccionario Hispanoamericano (2012). Derecho Tributario Tomo II. (1a. ed.). Barcelona: Espasa. Libros S.L.U.

Durango, R. (2016). Perspectivas del Derecho Tributario. Revista Jurídica. Universidad Católica Santiago de Guayaquil, págs., 27-28-29

Ecuador. Leyes y Decretos. (s.f). Constitución de la República del Ecuador. 1e. Quito: Ecuador.

Elizalde, M. (2015). Manual de Derecho Tributario. (1ª. ed.), Asunción: Liticolor.

Endara, C. (2011). El Recargo en materia Tributaria como recurso para evitar la evasión

fiscal. Quito, EC: Universidad de las Américas.

Franco Machado vs Directora Regional Norte del S.R.I., 38 GJ (C.N.J. 2010).

García, B. (2016). Revisión parcial del concepto de la tasa como especie tributaria. (Argentina). Revista Jurídica La Ley, 20(1), 853-864

García, H. (2010). La equidad y la proporcionalidad como base del impuesto en Derecho tributario: Doctrinas Esenciales. (1a. ed.), Buenos Aires: Abeledo-Perrot.

Ibarra, R. (2005). Temas actuales de Derecho Tributario: (1a. ed.), Barcelona: J.M. Bosch Editor

Julio Mera Vs Dirección Regional Norte del S.R.I., 12 GJ (C.C.E. 2017).

Lascano, C. (2010), Derecho Formal o Administrativo Tributario. (1ed.). Buenos Aires-Pudeleco.

Ley Orgánica de Régimen Tributario Interno. R.O. 500 del 6 de enero del 2009 del 2007

Mejía Juan, María Alarcón, Jaime Vernaza, Solah Peñáherrera vs Director General y Regional Sur del S.R.I., 48 G.J. (C.C.E. 2018).

Mogroviejo, J. (2011). Las Sanciones en materia tributaria (Ecuador). Revista de Derecho UASB, 15(1), 27-36

Nagua, J. (2011). La naturaleza jurídica del Recargo. Corte Nacional de Justicia, Jurisprudencia Nacional. Ciencia y Derecho, Quito-Ecuador, Editado por la Corte Nacional de Justicia Oñate, D. (2014). Análisis de la aplicación del recargo del $20 \%$ a la determinación realizada por la Administración Tributaria. Sus efectos jurídicos - económicos en el Ecuador y su posible Solución. Quito, EC: Universidad Central del Ecuador.

Ortiz, E. (2014). Naturaleza Jurídica del recargo del 20\% que establece en el Artículo 90 del Código Tributario. Quito, EC: Universidad Central del Ecuador.

Ossorio, M. (2007). Diccionario de Ciencias Juridicas, Politicas y sociales. (1a. ed.). Buenos Aires-Heliasta.

Patiño, V. (2013). Curso de Finanzas y Derecho Tributario. (1a. ed.). Asunción: Liticolor Pérez, A. (2005). El Derecho Tributario: Derecho financiero y tributario. (1a. ed.). Lima: Justo Valenzuela.

Poligráfica S.A. vs Director Regional del S.R.I. del Litoral Sur y el Director General del S.R.I., 52 GJ (C.N.J. 2011).

Rodríguez, C. (2005). Derecho Financiero y Tributario. (1ª. ed.) . Buenos Aires: Astrea. Salazar Miller, Vanesa Guzmán vs Director Regional y Regional Norte del S.R.ı., 66 GJ (2018) Sánchez, P. (2010). El recargo del 20\% sobre la determinación que realiza la administración. Quito, EC: Universidad Andina Simón Bolívar.

Thiago Ribeiro vs Director General y Regional Norte del S.R.I., 26 GJ (C.C.E 2010),

Toscano, L. (2006). Procedimientos administrativos y contenciosos en materia tributaria.

(2a. ed.) Quito: Dykinson.

Villegas, H. (2009). Derecho Administrativo Tributario. Buenos Aires: Astrea. 